\title{
Investigation of Adsorption based Air-condition System Committed for Colling of Truck Compartment
}

\author{
Dr. Harish Tiwari
}

\begin{abstract}
Presented system delivers improvement with investigation adsorption cooling framework controlled by fumes heat with just two governor valves. The refrigeration limit with respect to a truck lodge is evaluated as 1 TR a size of 3.5:1 is chosen and a model of $1 \mathrm{~kW}$ has been proposed and experimentation has been confirmed in the laboratory. A cooling impact between 1 to $1.2 \mathrm{~kW}$ has been acquired. The COP of the framework is in the scope of 04 to 0.45 . The components of the proposed framework are minimal which makes the system compact and portable. Proposed system shows effectually adjustable to become reconcile in transport truck. The all over weight of the structure for a cooling limit of $1 \mathrm{~kW}$ is $30 \mathrm{~kg}$. The warming time required to accomplish the cooling impact is around 10 minutes. Proposed framework challenges the issue of lodge and or compartment cooling of truck without influencing fuel utilization. The adsorber utilized are inventive two fold pipe mechanism for exchanging the heat providing improved transmission of along with fewer value of back pressure.
\end{abstract}

Index Terms - Adsorption cooling; Fumes heat; Reconcile in transport truck; Refrigeration; Truck compartment.

\section{INTRODUCTION}

In India highway transport is a noteworthy method of vehicle for merchandise over huge distances. In summer time, the air temperature in certain portions of India associates up to $45 \mathrm{oC}$. In such condition the temperature inside the lodge and or compartment of transport truck even surpasses $55^{\circ} \mathrm{C}[1]$. So there is a need of cooling framework to keep the temperature of the lodge in control. For vehicle cooling system, ordinarily vapor pressure based refrigeration cycle is utilized. The cycle keeps running over locomotive power and spends about $10 \%$ of the all out power delivered by the engine and in this manner builds the fuel utilization [2]. It influences overall transportation cost and hence not a worthy solution for cooling the truck cabinet. From temperature balance computations, it is evident that big amount of input heat measures contribution of around $30 \%$ of the complete heat provided goes away with exhaust gasses. Also, around $30 \%$ is leaving with cooling water. Among this, nearby $60 \%$ a section can be utilized to create the required refrigerating impact for lodge cooling. 1 TR of coolant is

Manuscript revised August 19, 2019 and published on September 10, 2019

Dr. Harish Tiwari, Department of Mechanical engineering, PCCOER, Ravet, Pune, Maharashtra, India required to for cooling the cabinet of truck. As the capacity of the automobile engine is at least $100 \mathrm{KW}$, considering the heat balance and the required measure of amount for driving a heat worked cycle, it is seen that fuel savings are approximately $10 \%$. The accessible heat-generated cooling alternatives were assessed fundamentally. The refrigeration based on adsorption cycle is observed to be appropriate for vehicular trucks. Carbon and ammonia are chosen as the reasonable adsorbent- coolant pair. The fundamental downside of the present frameworks examined in the Literature is countless control valves, which builds spillage issues and hence diminishes dependability of the framework. In the present work an imaginative adsorption refrigeration framework for lodge cooling of truck utilizing engine exhaust-fumes is exhibited.

The implication of the proposed system is to provide refrigeration without any impact on the working efficiency of the vehicular engine. Further the proposed framework utilizes non CFC coolant and in this way it has minimal impact on atmosphere. In the proposed work the structural of a model of $1 \mathrm{KW}$ limit is proposed. It is chosen to build up the model first to check the viable possibility of the proposed framework. The model is verified by means of experimentations in the research facility under simulated variable conditions of road.

The principal car cooling framework depended on Vapour Compression Refrigeration framework (VCR) and was presented by Packer in 1939. Over the most recent 70 years, vehicle cooling framework has experienced steady and constant enhancements in execution and proficiency because of upgrades in the individual segments of components. A portion of the elective advancements which may be changes engine-driven schemes can be Solid adsorption cooling frameworks, Absorption cooling, Stirling cycle cooling, Thermo acoustic refrigeration, dynamic attractive regenerator framework, thermo electric gadgets [3]. These schemes are still in phases of development. Vapour absorption framework and adsorption framework are observed to be most encouraging for vehicles, but all intents and purposes, there are certain weaknesses for vapor absorption frameworks for versatile applications and it is likewise troublesome with littler capacities. At present no VAR framework is accessible in market for limits up to 10 $\mathrm{kW}$ [4].

A solid vapour adsorption is same as like fluid vapour absorption scheme, where the refrigerant is adsorbed at the outside of another solid known as adsorbent. The introductory report of Metrons Transportation focus proposes 
the reasonableness of Adsorption scheme for vehicles [5]. The report exhibits the comparison of VCR framework and VAR framework.

Large number of experimentations conveyed test results proposes about the attainability of adsorption frameworks. $\mathrm{NH} 3$ - enacted carbon has been recommended as refrigerant adsorbent pair.

Saha et al [6] in the exhibited work have shown double mode silica gel water adsorption chillers plan alongside different temperature goes and got ideal outcomes for temperature scope of $50{ }^{\circ} \mathrm{C}$ and $55{ }^{\circ} \mathrm{C}$. Correlation of COP has been introduced for three phase mode and single stage numerous modes. Reenactment has been displayed and the COP is in the scope of 0.2 and 0.45 separately. [5] have exhibited the accomplishments in strong sorption refrigeration models, acquired since the enthusiasm for sorption framework was reestablished toward the part of the bargain. The applications included ice making and cooling [6] in his work professed to get COP of 0.15 for sun based application.

This paper shows a comprehensive survey on the past endeavors in the field of adsorption cooling frameworks for truck. Further the frameworks examined in literature are not exceptionally straightforward in operation. The more number of valves and spillages are serious issues.

Due to these issues the adsorption refrigeration framework couldn't turn into a down to earth arrangement. These issues are proposed to be comprehended in the present work.

\section{Proposed System ANd Adopted Methodology}

The test mechanical assembly would used supply those fundamental heat of the adsorber for IC engine. The schematic framework of the skeleton may be provided for in figure 1. Those set up comprises for two adsorber, two condensers Also person evaporator. The condensers are connected with evaporator through control valves. Two adsorber beds are suggested person over warming mode another On cooling mode. A standout amongst those adsorber will be blamed for refrigerant soluble base. Two condensers, particular case evaporator. Two control valves What's more particular case evaporator need aid connected Likewise showed up over fig. 2. The condensers more evaporator is fitted for a fan for compelled wind engine debilitate gasses enter those adsorber stacked up for ammodytidae with warm the adsorber couch toward reliable impostor. Adsorber rejects those refrigerant for those adsorption for warmth Similarly as the adsorptivity may be a part from climb in temperature. Those refrigerant gets compacted in perspective for warming In reliable impostor. Those stuffed refrigerant dives will condenser through control valve.

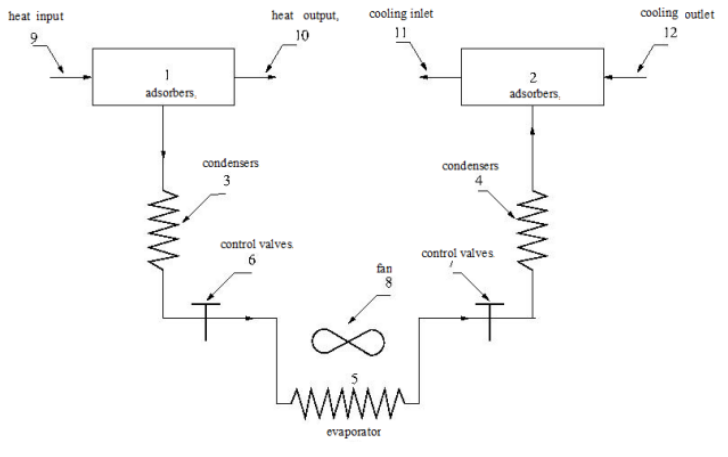

Fig.1. Layout of proposed system

Rfrigerant which may be done vaporous state may be thick in the condenser In secondary weight dependent upon the barometrical temperature. Ahead you quit offering on that one side for control valve those weight may be helter skelter Also on the inverse side of control valve the weight will be low. The control valve outlet may be connected with alternate adsorber. All heat development coefficients, $U_{0}$ depends inside and outside heat development coefficients and the conductance through steel tubes and adsorbing material. It will be decided using large heat exchange through compound chamber the zone required for high temperature move should supply the heat of $2 \mathrm{KW}$ of the adsorber that will be dictated as Aad $=0.6 \mathrm{~m}^{2}$. Previously, cooling mode through evaporator and other condenser. Adsorber are chosen shown in table 1 .

TABLE I: Adsorber Parameters

\begin{tabular}{ll}
\hline \hline Adsorber temperatures & $160{ }_{\mathrm{o}}^{\mathrm{C}}$ \\
\hline refrigerating impact & $1 \mathrm{KW}$ \\
\hline warmth of dissipation of alkali (L) & $1035 \mathrm{~kJ} \mathrm{~kg}-1$. \\
\hline idle heat as & $0.45 \mathrm{~kg}$ \\
\hline Thickness of adsorbing material & $680 \mathrm{~kg} \mathrm{~m}^{-3}$ \\
\hline \hline
\end{tabular}

It is provided for Eventually described in (1) and condition (2).

$$
\begin{gathered}
\text { Qsensible, heating }=\frac{[(\mathrm{mad} \times \mathrm{Cpad} \times \Delta \mathrm{Tad})+(\mathrm{mst} \times \mathrm{Cpst} \times \Delta T \mathrm{Tst})]}{\Delta t} \\
\text { Qlatent heating }=\frac{[\operatorname{mad}(X 2-X 1) \times(H 2-H 1)]}{\Delta t}
\end{gathered}
$$

$$
\text { Qadsorber }=\text { Qasensible, heating }+ \text { Qlatent heating }
$$

The temperature needed should high temperature or cool the adsorber (Qad,heating) will be ascertained. Qad,heating $=2$ kw to getting An cooling impact about $1 \mathrm{kw}$.

The heat exchange region may be computed from the Emulating (3).

$$
Q=U \times A \times \Delta T a d
$$




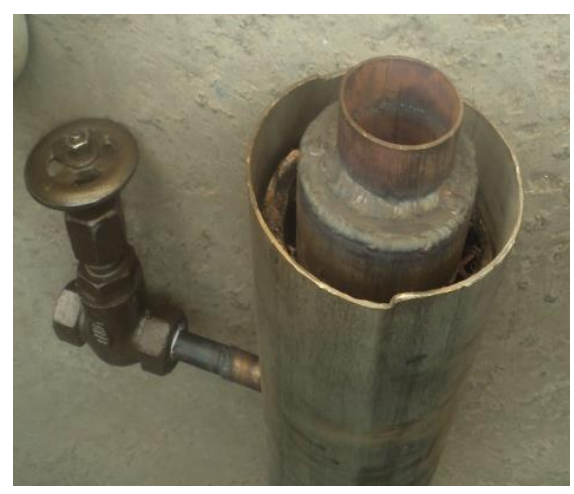

Fig. 2. Adsorber.

The zone approachable for heat move to this circumstance is $0.45 \mathrm{~m}^{2}$. Balances would provided for on the focus shell and inside those central barrel stretches the zone will around $0.8 \mathrm{~m}^{2}$. This locale ought on make sufficient for warmth move. The most recent estimations and standard highlights of the adsorber of the schema need aid provided for clinched alongside table 2 .

Condenser will make uncovered with climatic air striking with truck couch speed. Temperature distinction may be expected will make $7^{\circ} \mathrm{C}$. Qc $=2 \mathrm{KW}$. The standard condenser utilized within automobiles need been utilized to the experimentation.

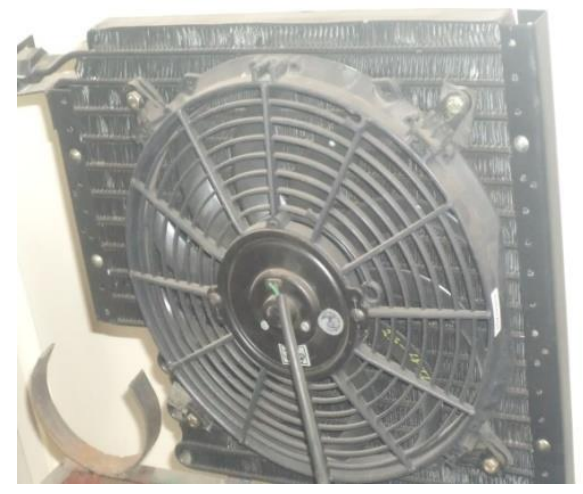

Fig. 3. Condenser.

TABLE II: Main feature of the Adsorption refrigeration system

\begin{tabular}{ll}
\hline \multicolumn{2}{c}{ System } \\
\hline Parameter & Values of Observations \\
\hline Refrigerant used & Ammonia \\
\hline Adsorbing material (coconut shell) & Charcoal $4 \mathrm{~mm}$ granule size \\
\hline Mass of adsorbing material in adsorber & $1.8 \mathrm{~kg}$ \\
\hline Mass of refrigerant & $0.6 \mathrm{~kg}$ \\
\hline Weight of each adsorber & $10.5 \mathrm{~kg}$ \\
\hline Length and Diameter of adsorber & $1.1 \mathrm{~m} \mathrm{and} 110 \mathrm{~mm}$. \\
\hline Weight of condenser with fan & $2.4 \mathrm{~kg}$ \\
\hline Weight of evaporator & $2.4 \mathrm{~kg}$ \\
\hline Overall weight of the system & $30 \mathrm{~kg}$ \\
\hline Number of control valves & 2 \\
\hline Control valve size & $10 \mathrm{~mm}$ \\
\hline \hline
\end{tabular}

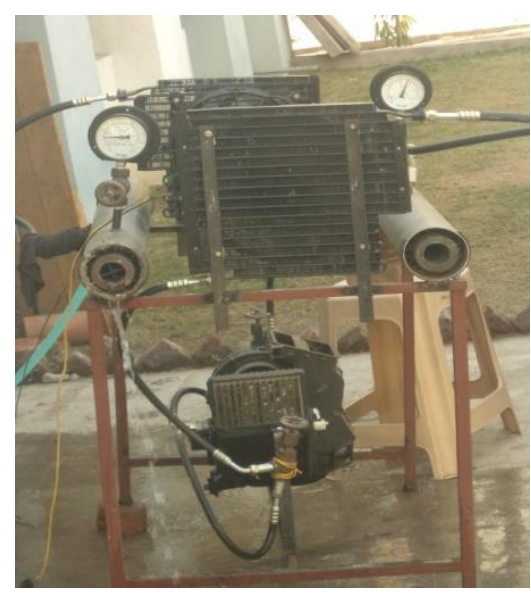

Fig. 4. Experimental set up

A fan may be fitted of the condenser to consolidating the refrigerant in the condenser. Condensers would two done amount Furthermore need aid associated with every adsorber. The outlet of the condenser may be associated with control valves. The condenser will be demonstrated to fig. 3 .

\section{RESUltS AND DiscuSSIONS}

A progression of analyses has been completed on the created trial set up in the research facility. The fumes gases are gone through adsorber I which is in heating mode. Adsorber II is in cooling mode and is cooled by water flow. Both the control valves are in shut position. The weight begins expanding. The readings are recorded according to the method clarified in past area of framework working. The outcomes are shown with the assistance of the accompanying Figures (Figure 5 to Figure 8). Chart 1 is called an isotherm is a diagram drawn between mass of the refrigerant ingested at different weight in the adsorber at consistent temperature. It is as appeared in Graph 1.

Thus different charts have been shown for investigation purpose about the refrigerating impact, $\mathrm{COP}$ at different fumes gas temperatures. Heating time which is a significant parameter in adsorption refrigeration has additionally been recorded and plotted at different fumes gas temperatures.

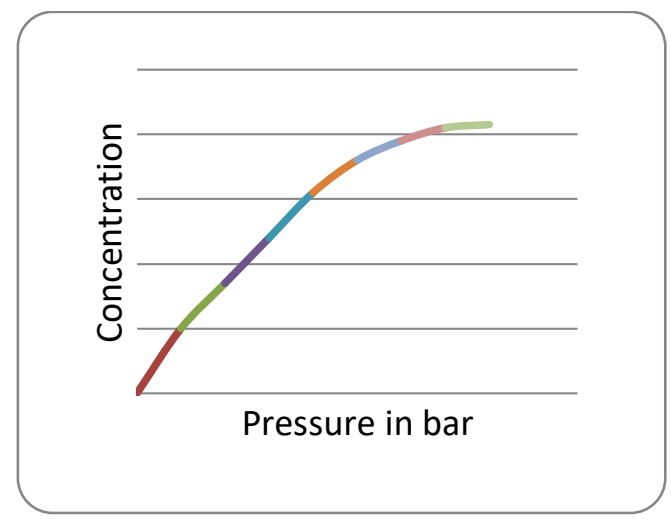

Fig. 5. Isotherm (pressure Vs $X$ at constant $T$ ) 


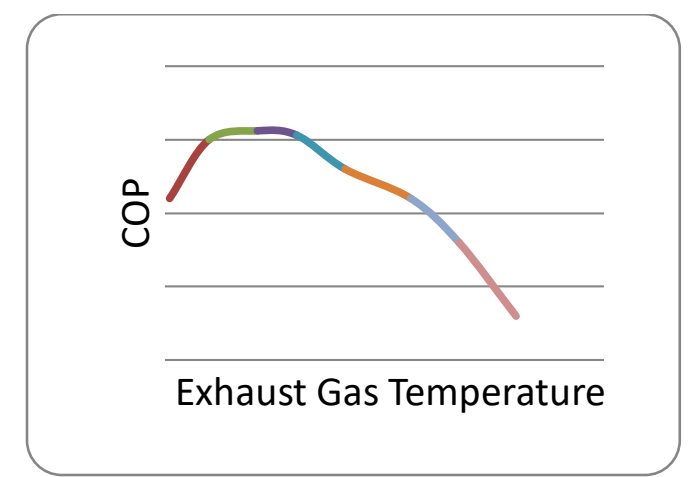

Fig. 6. Graph between Tex Vs. COP

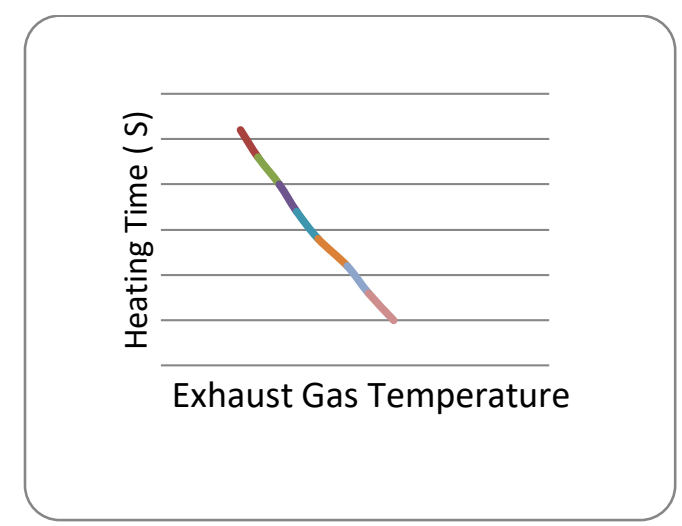

Fig. 7. Graph between $\Delta t$ Vs Tex.

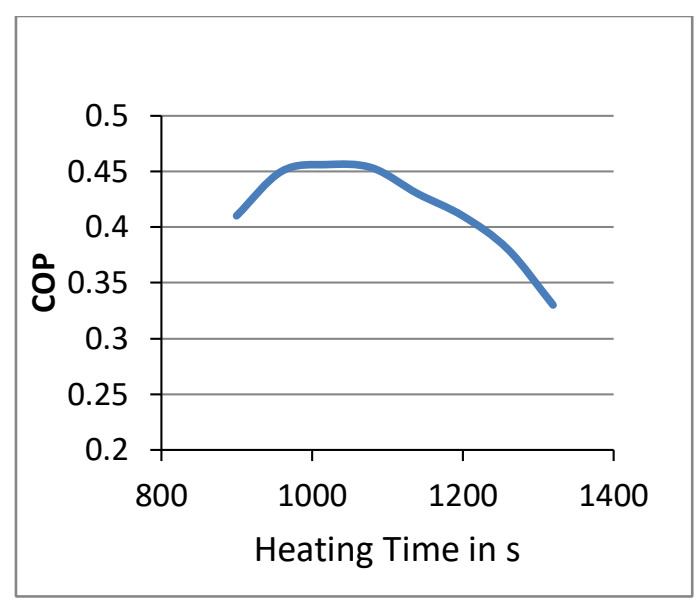

Fig. 8. Graph between COP Vs. $\Delta t$

\section{Conclusions}

The engine power required to run a cooling framework can be saved by utilizing waste heat controlled cooling framework. The proposed cooling structure ran by frameworks with incited carbon and NH3. Similarly as adsorbent refrigerant sets may be picked and used. In the recommended plan sloid material will be used as adsorber which makes framework sensible to versant provisions. The cop of the skeleton will be around 0.45 to a cooling farthest point of $1 \mathrm{kw}$. Those all load of the framework to cooling breaking point of $1 \mathrm{TR}$ is $30 \mathrm{~kg}$. Proposed framework may be altogether preservationist and could make presented for a truck couch. It reduced number about valves makes those schema progressively dependable furthermore spillage spare. The novel heat exchanger as adsorber exchanges for warming and cooling.

\section{REFERENCES}

[1] Alam, S, "A proposed model for utilizing exhaust heat to run automobile air-conditioner", The 2nd Joint International Conference on Sustainable Energy and Environment, Bangkok, Thailand, pp. 21-23, November 2006,.

[2] Harish Tiwari, Dr. G. V. Parishwa, “Adsorption Refrigeration System for Cabin Cooling of Trucks", International Journal of Emerging Technology and Advanced Engineering, ISSN 2250-2459, Volume 2, Issue 10, October 2012

Aprachi, V., Kao S. H., Selamet A., Introduction to heat transfer, 1999, Prentice Hall, Inc. Upper Saddle River, NJ, U.S.A.

[3] Furzanchy, A., Ali, A. and Tootoonchi, "Controlling automobile thermal comfort using optimized fuzzy controller", Applied Thermal Engineering, pp. 1267 - 1270, May 2008.

[4] Kong, X., Wang, R., Wu, J., Hung, X., Huang, Y., Wu, D. and Yu, Y., "Experimental investigation of a macro combined cooling, heating and power system by a gas engine", International journal of refrigeration, pp. $77-87$, September 2005.

[5] Tumainot, Z., Metacolf, S. and R. Critoph, "Novel compact sorption generators for car air conditioning", International journal of Refrigeration, pp. 727 - 733, May 2009.

[6] Wang R. and Oliveira, R., " Absorption refrigeration an efficient way to make good use of waste heat and solar energy", International sorption Heat Pump Conference, Denver, June 22, 2005.

\section{AUTHORS PROFILE}

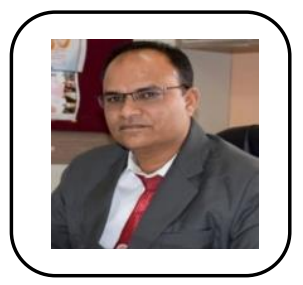

Dr. Harish U. Tiwari currently working as Principal at Pimpri Chinchwad College of Engineering \& Research, Ravet, Pune-412101. I have personally filled 19 patents in field of refrigeration, electronics, mechanics, etc., and assisted around 200 patents, and wishing to commercialize those patents. 